\title{
The stereoisomeric Bacillus subtilis HN09 metabolite 3,4-dihydroxy-3-methyl-2- pentanone induces disease resistance in Arabidopsis via different signalling pathways
}

Niu Liu ${ }^{1+}$, Xiao Luo ${ }^{1+}$, Yongqing Tian', Duo Lai ${ }^{3}$, Longlai Zhang ${ }^{1}$, Fei Lin ${ }^{1,2^{*}}$ and Hanhong X ${ }^{1 *}$ (i)

\begin{abstract}
Background: Plant immune responses can be induced by plant growth-promoting rhizobacteria (PGPRs), but the exact compounds that induce resistance are poorly understood. Here, we identified the novel natural elicitor 3,4dihydroxy-3-methyl-2-pentanone from the PGPR Bacillus subtilis HN09, which dominates HNO9-induced systemic resistance (ISR).

Results: The HNO9 strain, as a rhizobacterium that promotes plant growth, can induce systemic resistance of Arabidopsis thaliana plants against Pseudomonas syringae pv. tomato DC3000, and the underlying role of its metabolite 3,4-dihydroxy-3-methyl-2-pentanone in this induced resistance mechanism was explored in this study. The stereoisomers of 3,4-dihydroxy-3-methyl-2-pentanone exhibited differential bioactivity of resistance induction in A. thaliana. B16, a 1:1 mixture of the threo-isomers $(3 R, 4 S)$ and $(3 S, 4 R)$, was significantly superior to B17, a similar mixture of the erythro-isomers $(3 R, 4 R)$ and $(3 S, 4 S)$. Moreover, B16 induced more expeditious and stronger callose deposition than B17 when challenged with the pathogen DC3000. RT-qPCR and RNA-seq results showed that B16 and B17 induced systemic resistance via JA/ET and SA signalling pathways. B16 and B17 activated different but overlapping signalling pathways, and these compounds have the same chemical structure but subtle differences in stereo configuration.
\end{abstract}

Conclusions: Our results indicate that 3,4-dihydroxy-3-methyl-2-pentanone is an excellent immune elicitor in plants. This compound is of great importance to the systemic resistance induced by HN09. Its threo-isomers $(3 R, 4 S)$ and $(3 S, 4 R)$ are much better than erythro-isomers $(3 R, 4 R)$ and $(3 S, 4 S)$. This process involves SA and JA/ET signalling pathways.

Keywords: PGPR, ISR, Metabolite, 3,4-dihydroxy-3-methyl-2-pentanone, Stereoisomer

\footnotetext{
* Correspondence: resistanc@scau.edu.cn; hhxu@scau.edu.cn

${ }^{\dagger}$ Niu Liu and Xiao Luo contributed equally to this work.

${ }^{1}$ State Key Laboratory for Conservation and Utilization of Subtropical

Agro-Bioresources/Key Laboratory of Natural Pesticide and Chemical Biology,

Ministry of Education, South China Agricultural University, Guangzhou

510642, China

Full list of author information is available at the end of the article
}

(c) The Author(s). 2019 Open Access This article is distributed under the terms of the Creative Commons Attribution 4.0 International License (http://creativecommons.org/licenses/by/4.0/), which permits unrestricted use, distribution, and reproduction in any medium, provided you give appropriate credit to the original author(s) and the source, provide a link to the Creative Commons license, and indicate if changes were made. The Creative Commons Public Domain Dedication waiver (http://creativecommons.org/publicdomain/zero/1.0/) applies to the data made available in this article, unless otherwise stated. 


\section{Background}

Plant growth-promoting rhizobacteria (PGPRs) that colonize host roots can improve disease resistance and promote plant growth [1-3]. Most PGPRs generate a series of secondary metabolites [4] as the elicitors of plant defense response, thus directly or indirectly triggering induced systemic resistance (ISR). To date, many elicitors have been characterized. M-cresol and methyl benzoate (MeBA), as active volatile compounds from Ampelomyces sp. and Cladosporium sp., respectively, can produce ISR against pathogens [5]. The volatile organic compounds (VOCs) 2,3-butanediol and 3-methyl-1-butanol identified from B. subtilis GB03 and B. amyloliquefaciens IN937a confer ISR against the bacterial pathogen Erwinia carotovora subsp. Carotovora [1, 6]. Exopolysaccharides, 2,3-butandiol, bacilysin, difficidin, macrolactin, bacillaene, surfactin, bacillomycin D and fengycin, which are B. amyloliquefaciens SQR9 metabolites can improve systemic resistance against $P$. syringae pv. tomato DC3000 and Botrytis cinerea [7].

After elicitors are recognized, ISR is triggered in plants by activation of jasmonic acid (JA), ethylene (ET) and salicylic acid (SA) signalling [8], which are interconnected by complex signalling networks and crosstalk [9]. The molecular basis of this type of ISR has been widely described. From A. thaliana mutants impaired in JA or ET signalling, it was found that JA and ET can regulate rhizobacterium-mediated ISR [10]. Proteomic analysis indicated that bacterial volatiles produced by $B$. subtilis GB03 significantly induced the upregulation of ET biosynthesis enzymes [11]. B. amyloliquefaciens NC6 can produce the PeBA1 protein, which induces systemic resistance against pathogens, including fungal pathogen $B$. cinerea and tobacco mosaic virus (TMV). After treatment with PeBA1, the SA-responsive PR1a, PR1b, PR5, and $P A L$, as well as the JA-responsive PDF1.2 and COI1, were upregulated.

The chiral configuration of elicitors significantly affects their biological activity. GB03-synthesized (2R,3R)-butanediol triggered ISR against Erwinia carotovora ssp. carotovora SCC1 in Nicotiana tabacum, but another stereoisomer, (2S,3S)-butanediol, did not have the same effect [1, 12]. Similarly, herbivore elicitor volicitin has obvious structural specificity of insect-derived elicitors. The compound has active L-isomer, but inactive D-isomer [13]. The existence of stereoisomer specificity has been demonstrated in PGPR metabolites, but reports on the comparison of specific ISR signaling pathways activated by chiral compounds are limited, partly due to the technical difficulty associated with separating stereoisomers. Although chiral compounds are structurally similar, they are actually two different substances and often have distinct functions. The separation of chiral compounds and comparison of the resistance-related signalling pathways activated by these compounds are important. Such studies understand the plant immune responses mechanically and allow identification of novel chemical inducers through rational design.

B. subtilis HN09 induces resistance to many plant diseases depending on the secondary metabolites. The $(3 R, 4 S)$ and $(3 S, 4 R)$ 3,4-dihydroxy-3-methyl-2-pentanone 1:1 racemate B16 and $(3 R, 4 R)$ and $(3 S, 4 S)$ 3,4-dihydroxy-3-methyl-2-pentanone 1:1 racemate B17 were isolated from HN09 culture filtrate and were verified to be involved in the HN09-induced systemic resistance to P. syringae pv. tomato DC3000 in A. thaliana. Our data showed a significant difference between the abilities of B16 and another pair of stereoisomers, B17, to elicit defence responses at the plant, cellular and molecular levels.

\section{Results \\ HN09 metabolites induce resistance in A. thaliana}

The metabolites of PGPRs play important roles in ISR. PGPR B. amyloliquefaciens SQR9 can induce systemic resistance against P. syringae pv. tomato DC3000 and Botrytis cinerea. However, the mutants of SQR9 strain, which can weaken the induced plant resistance to phytopathogens, were deficient in the production of extracellular compounds, including exopolysaccharides, 2,3-butandiol, bacilysin, difficidin, macrolactin, bacillaene, surfactin, bacillomycin D and fengycin [7]. B. subtilis HN09 strongly enhanced systemic resistance to Magnaporthe oryzae and Fusarium oxysporum f. sp. radicis-lycopersici in rice and tomato (Additional file 1: Figure S1) and significantly promoted the growth of A. thaliana (Additional file 2: Figure S2). To further determine whether the PGPR HN09-induced systemic resistance was dependent on the metabolites of this organism, we examined the ability of HN09-C (containing only HN09 cells), HN09-S (containing only HN09 metabolites) and HN09-FB (containing both HN09 cells and metabolites) to induce resistance against DC3000. The leaves of plants treated with HN09-C showed typical symptoms of bacterial speck disease, and the yellow or water-soaked spots are surrounded by chlorosis (Fig. 1a). HN09-FB and HN09-S significantly reduced pathogen growth in leaves (Fig. 1b). These data suggested that HN09 metabolites indeed induced systemic resistance against DC3000 in plants, but HN09 bacterial cells did not have the same effect.

\section{Compound spectroscopic data and structure determination}

To identify active compounds among HN09 metabolites, we separated the metabolites from the HN09 culture filtrate and obtained two active compounds, namely, B16 and B17. B16 was obtained as a colourless oil ; $[a]_{\mathrm{D}}^{24} \pm 0^{\circ}$ $(\mathrm{c}=0.202, \mathrm{MeOH}) ;$ positive EI-MS $\mathrm{m} / \mathrm{z}: 133[\mathrm{M}+\mathrm{H}]+$, $155[\mathrm{M}+\mathrm{Na}]+1 ; 1 \mathrm{H}$ NMR $(600 \mathrm{MHz}, \mathrm{MeOD}) \delta 3.83$ 


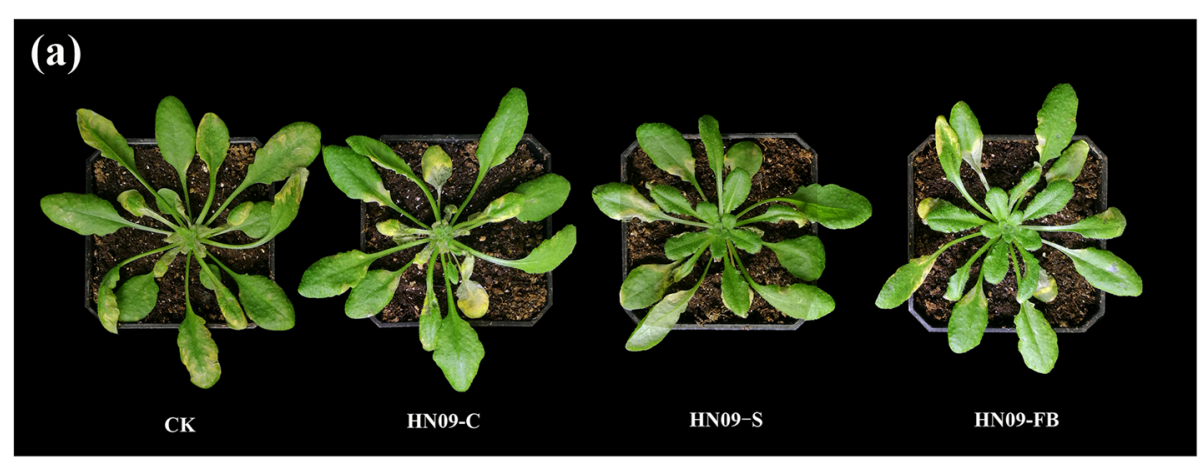

(b)

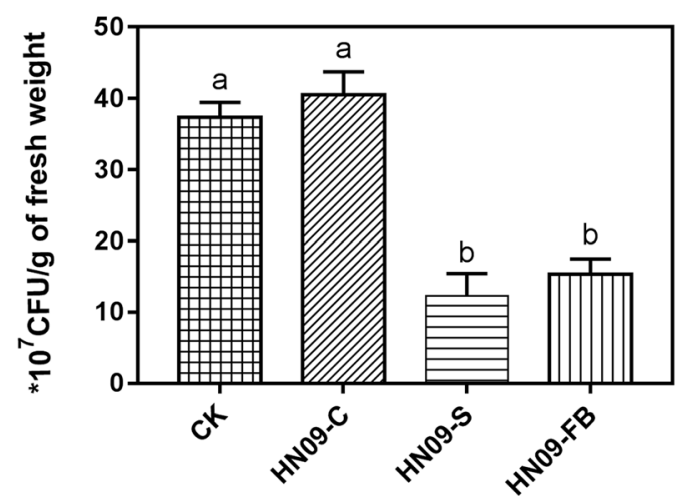

Fig. $1 \mathrm{HN} 09$ metabolites induce resistance in A. thaliana. Induction of systemic resistance to Pseudomonas syringae pv. tomato DC3000 in A. thaliana Col-0 plants treated with HN09 and its fermentation broth. A. thaliana Col-0 plants were treated with HN09 bacteria cells (HN09-C), HN09 fermentation broth at $\mathrm{OD}_{600}=0.1$ (HNO9-FB), supernatant of HN09 fermentation broth (HNO9-S) and $10 \mathrm{mM} \mathrm{MgSO}_{4}$ (CK). Five days later, leaves were sprayed with a cell suspension of DC3000 at $\mathrm{OD}_{600}=0.02$. (a) Representative plants of HN09-C, HN09-S and HNO9-FB were photographed 5 days post inoculation (dpi). (b) Colony density of DC3000 in the leaves of A. thaliana plants of different treatment groups. Values are the average CFU per gram of leaf; each treatment had 12 plants, and 3 leaves per plant were obtained for quantification of DC3000 density (least significant difference test; $P<0.05)$. All experiments were conducted twice with similar results

$\left(\mathrm{q}, \mathrm{J}=6.0 \mathrm{~Hz}, 1 \mathrm{H}, \mathrm{H}^{-4}\right), 2.24(\mathrm{~s}, 3 \mathrm{H}, \mathrm{H}-1), 1.28(\mathrm{~s}, 3 \mathrm{H}$, $\mathrm{H}-6), 1.10(\mathrm{~d}, \mathrm{~J}=6.0 \mathrm{~Hz}, 3 \mathrm{H}, \mathrm{H}-5)$ 。13C NMR (150 $\mathrm{MHz}, \mathrm{MeOD}) \delta$ 215.81(C-2), 82.77(C-3), 72.61(C-4), 26.57(C-1), 21.39(C-6), 17.78(C-5) (Fig. 2).

$\mathrm{B} 17$ was also obtained as a colourless oil ; $[a]_{\mathrm{D}}^{24} \pm 0^{\circ}(\mathrm{c}=$ 0.277, $\mathrm{MeOH})$; positive EI-MS $\mathrm{m} / \mathrm{z}:[\mathrm{M}+\mathrm{H}]+=133$, $[\mathrm{M}+\mathrm{Na}]+=155 ; 1 \mathrm{H}$ NMR $(600 \mathrm{MHz}, \mathrm{MeOD}) \delta 3.97(\mathrm{q}$, $\mathrm{J}=6.0 \mathrm{~Hz}, 1 \mathrm{H}, \mathrm{H}-4), 2.26$ (s, 3H, H-1), 1.21 (s, 3H, H-6), 1.18 (d, J $=6.0 \mathrm{~Hz}, 3 \mathrm{H}, \mathrm{H}-5) .13 \mathrm{C}$ NMR $(150 \mathrm{MHz}$, MeOD) $\delta$ 215.23(C-2), 82.94(C-3), 72.50(C-4), 25.81(C-1), 22.02(C-6), 17.05(C-5) (Fig. 2).

The NMR data for B16 and B17 were very similar to those for 3,4-dihydroxy-3-methyl-2-pentanone [14]. Based on their optical rotation values, it was clear that both compounds were racemates composed of enantiomeric isomers. Therefore, B16 was identified as a $1: 1$ mixture of $(3 \mathrm{R}, 4 \mathrm{~S})$ - and (3S,4R)-3,4-dihydroxy-3methyl-2-pentanone, and B17 was identified as a 1:1 mixture of $(3 S, 4 S)$ - and $(3 R, 4 R)-3,4$-dihydroxy-3-methyl-2-pentanone (Fig. 2) [14].

\section{B16 and B17 induced resistance to $P$. syringae DC3000 in}

\section{A. thaliana}

Whether B16, B17 and their 1:1 mixture (Mix) can trigger ISR to DC3000 in A. thaliana plants were tested. Water was taken as the negative control, and ISR chemical benzothiadiazole (BTH) was the positive control. Five days after inoculation with DC3000, the plants treated with mock had typical DC3000 infection symptoms. The leaves were yellowing or had water-soaked spots which were surrounded by extensive chlorosis (Fig. 3a). Compared with the mock-treated plants, the disease area of the plants treated with B16- and B17 was much smaller. Moreover, in the plants treated with B16, B17, and Mix, the density of DC300 in leaves decreased by $67.03,52.18$ and $48.6 \% 5$ days after DC3000 inoculation compared with that in the mock-treated plants (Fig. 3b). In the BTH-treated plants, the density of DC3000 decreased by $83.43 \%$ (Fig. 3b). Interestingly, B16 exhibited significantly higher biocontrol activity against DC3000 than B17 and the mixture treatment. 
(a)<smiles>CC(=O)C(C)C(C)O</smiles>

(b)<smiles>CC(=O)[C@@](C)(O)[C@@H](C)O</smiles>

(c)

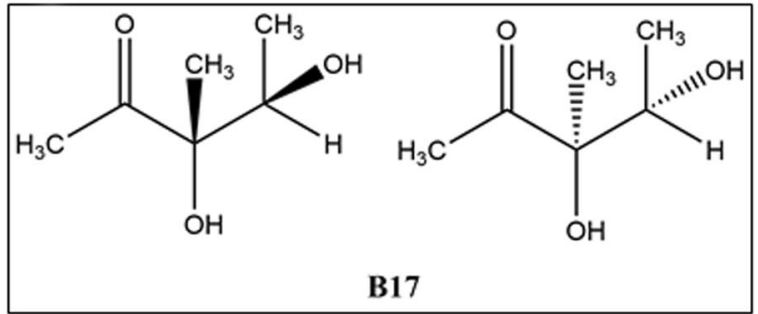

Fig. 2 (a) The structure of 3,4-dihydroxy-3-methyl-2-pentanone. (b) B16 was a 1:1 mixture of (3R,4S)- and (3S,4R)-3,4-dihydroxy-3- methyl-2pentanone. (c) B17 was a 1:1 mixture of $(3 \mathrm{~S}, 4 \mathrm{~S})$ - and (3R,4R)-3,4-dihydroxy-3- methyl-2-pentanone

To determine whether B16 and B17 had direct antibacterial activity against pathogens, we monitored the growth of DC3000 in liquid medium containing $100 \mu \mathrm{M}$ B16, B17, Mix, or the commercial fungicide Thiram (Table 1). Only B16 weakly reduced DC3000 growth, while Thiram completely eliminated the growth of the bacterium. This result excluded the antimicrobial activity of B16 and B17.

\section{B16 and B17 induced callose deposition in A. thaliana}

The priming mechanism of B16 and B17 for the enhanced activation of cellular defense responses in $A$. thaliana plants was examined. SA- or BTH- pretreated plants producing more callose deposits around the infection site $[15,16]$. After inoculation with DC3000 for 12 $\mathrm{h}$, callose deposition in the B16- and B17-treated $A$. (a)

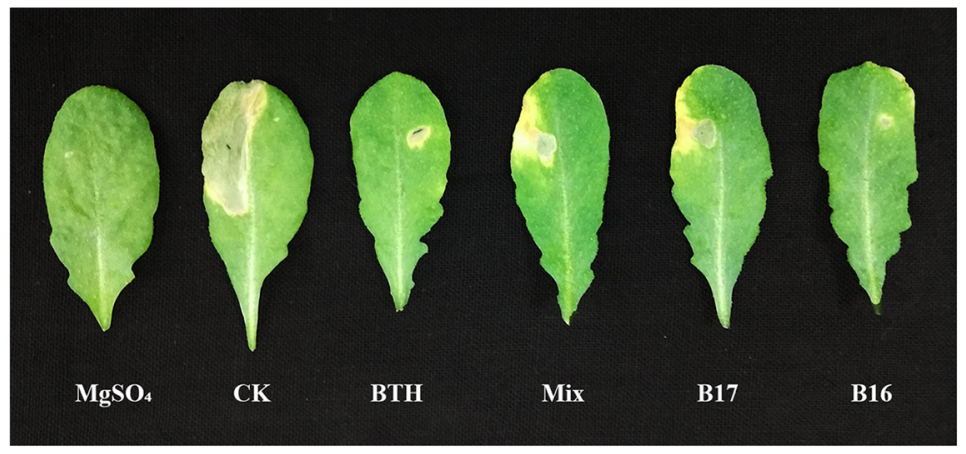

(b)

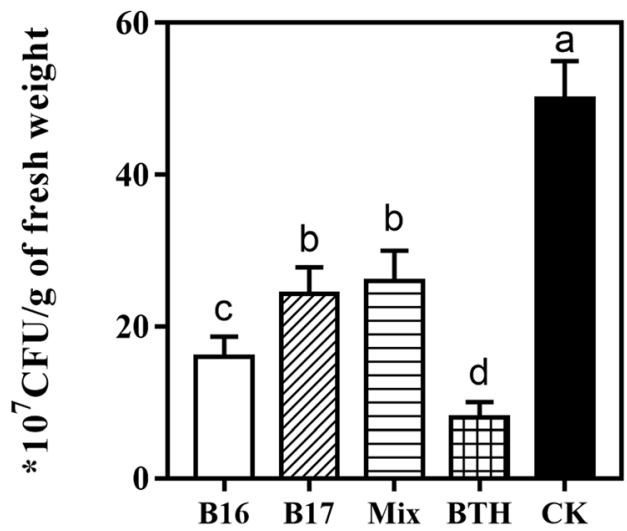

Fig. 3 B16 and B17 induced resistance to P. syringae DC3000 in A. thaliana. Four-week-old A. thaliana plants were treated with B16, B17, Mix, 100 $\mu \mathrm{M} \mathrm{BTH}$, and $10 \mathrm{mM} \mathrm{MgSO}_{4}$. After $24 \mathrm{~h}$, leaves were injected with a cell suspension of DC3000 at $\mathrm{OD}_{600}=0.001$ (a) Representative plants of the $\mathrm{B} 16, \mathrm{~B} 17, \mathrm{Mix}, \mathrm{BTH}, \mathrm{MgSO}_{4}$ and water treatments were photographed 5 days post inoculation (dpi), with BTH as a positive control, and $\mathrm{MgSO}_{4}$ and water as a negative control. (b) Colony density of DC3000 in the leaves of A. thaliana plants from different treatments. Values are the average CFU per gram of leaf, each treatment had 9 plants, and 3 leaves per plant were obtained for quantification of DC3000 density. Different letters indicate statistically significant differences between treatments (least significant difference test; $P<0.05$ ) 
Table 1 Antibacterial activity of different elicitors against DC3000 in vitro

\begin{tabular}{lll}
\hline Treatment & OD $( \pm$ SD $)$ & Inhibition $(\%)$ \\
\hline B16 & $0.721 \pm 0.153$ & 11.19 \\
B17 & $0.988 \pm 0.208$ & -21.71 \\
Mix & $0.967 \pm 0.285$ & -19.13 \\
Thiram & $0.141 \pm 0.018$ & 82.57 \\
CK & $0.811 \pm 0.157$ & - \\
\hline
\end{tabular}

thaliana leaves was observed, and the areas were 1.04 and $3.29 \mathrm{~mm}^{2}$, respectively; however, callose deposition was observed in neither the CK treatment nor the DC3000-inoculated leaves at the same time point (Fig. 4). At $24 \mathrm{hpi}$, these defence responses were not observed in the CK treatment, but the B16- and B17-treated plants exhibited larger callose deposition areas (109.29 and $35.99 \mathrm{~mm}^{2}$, respectively) than the plants inoculated with DC3000 alone $\left(16.69 \mathrm{~mm}^{2}\right.$ ) (Fig. 4). Importantly, B16 induced stronger callose deposition than B17.

\section{Defence-related enzyme activity}

To further verify the induction of disease resistance by B16 and B17, the activity of key defence-related enzymes in plants that were treated with B16 and B17 for $24 \mathrm{~h}$ was analysed. As a vital enzyme in phenolic biosynthesis, phenylalanine ammonia-lyase (PAL) connects primary metabolism (shikimic acid pathway) and secondary metabolism (phenylpropanoid pathway), catalyses the first step in phenylpropanoid biosynthesis and plays an essential role in defence responses [17]. The activity of PAL was significantly higher in the B16- and B17-treated plants than in the water-treated control, and the B16treated plants showed higher activity than the B17treated plants, and the activity was equal to that of the SA-treated positive control (Fig. 5a). BTH is a derivative of SA, and both of SA and BTH could be set up as positive control for this experiment. It would be better if used BTH as a positive control to be more consistent. But the phenomenon of SA increased the defence-related enzyme activities had been better described than those in BTH. So, we used SA as positive control in this experiment. The early stages of plant resistance response involve two reactive oxygen species (ROS), $\mathrm{H}_{2} \mathrm{O}_{2}$ and $\mathrm{O}_{2}{ }^{-}$, which can be induced by abiotic or biotic elicitors, but excess ROS are deleterious to plant cells [18]. Oxidative stress can be inhibited by peroxidase (POD). With higher ROS level, $\mathrm{H}_{2} \mathrm{O}_{2}$ is decomposed by POD by the oxidation of co-substrates like phenolic compounds. The construction, rigidification and eventual lignification of cell walls involve POD enzyme, which can avoid the damage of plant tissues [19]. In our study, in the B16- and B17-treated plants, the POD enzyme activity was significantly higher than that in the water-treated control and was equal that in the SA-treated positive control, which demonstrated that B16 and B17 could successfully elicit plant defence responses, similar to the phytohormone SA (Fig. 5b). 3 -1,3-glucan and other components of fungal

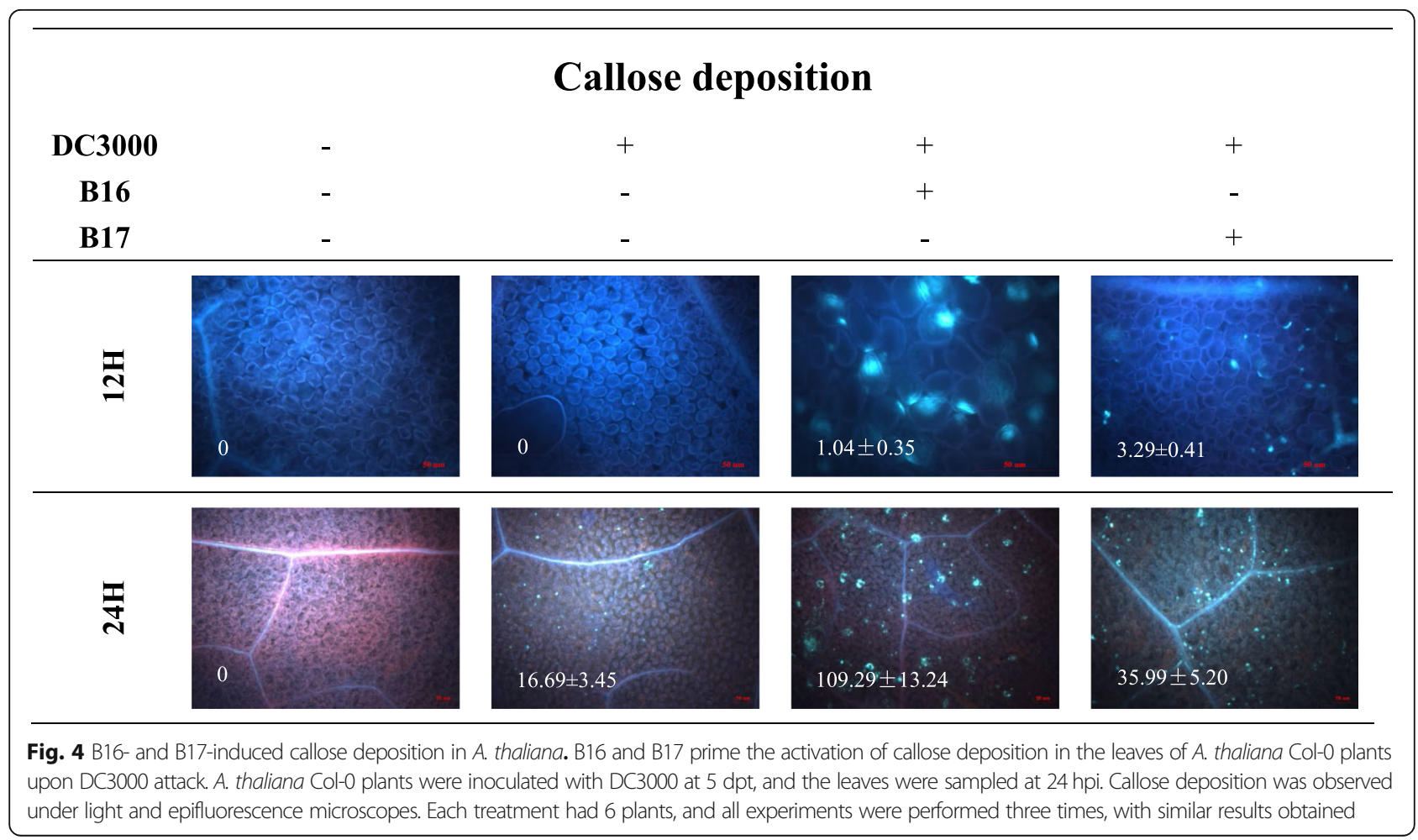




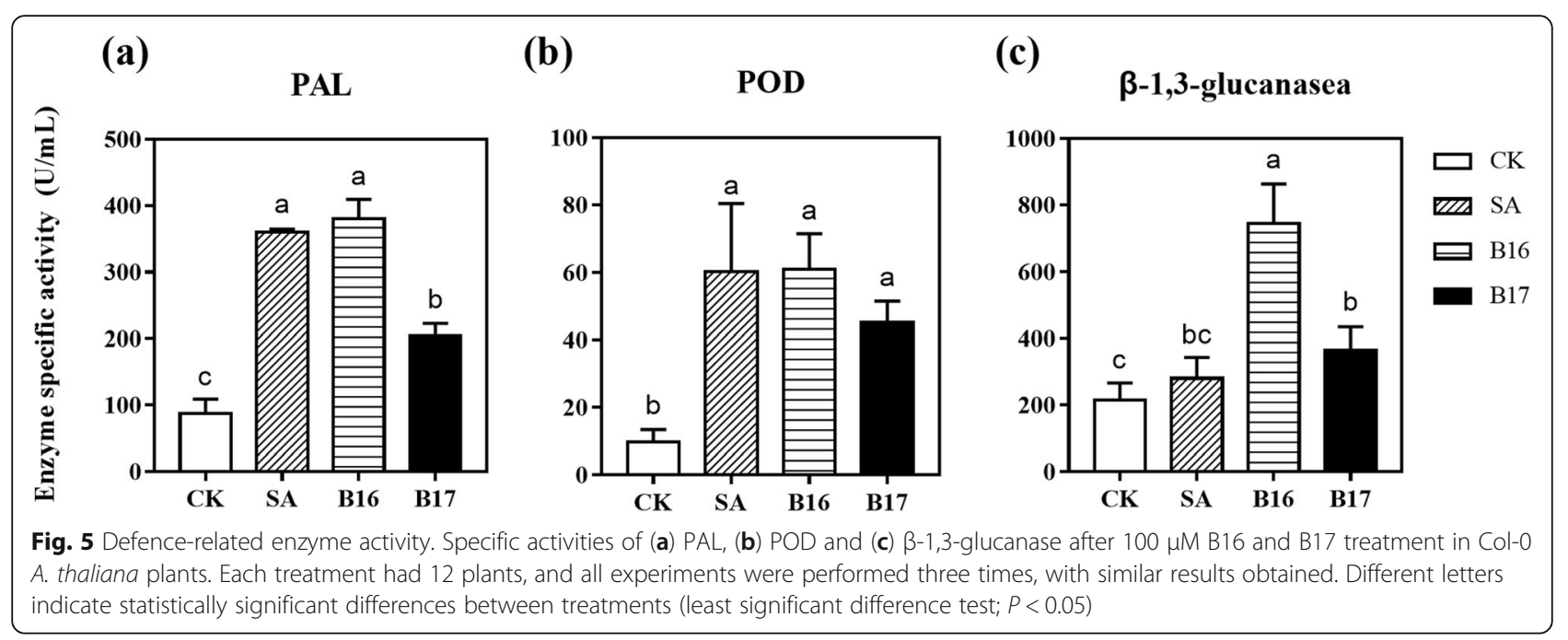

cell walls may be hydrolysed by pathogenesis-related proteins like $\beta-1,3-$ Glucanases, thus damaging propagule or pathogenic structures. Generally speaking, the accumulation of $\beta$-1,3-glucanase can indicate the induced resistance. Our results indicated that the activities of $\beta-1,3-$ glucanases in A. thaliana plants were markedly enhanced by B16 and B17, which indicated that the B16 and B17 treatments could increase plant resistance (Fig. 5c).

B16 and B17 induced defence-related gene expression in A. thaliana

The induction patterns of marker genes for these pathways in plants exposed to B16 and B17 were further studied, so that the role of SA-, JA- and ET-related signal transduction pathways in systemic resistance induced by B16 and B17 can be defined clearly. B16 and B17 were used to treat the plants for $24 \mathrm{~h}$. The transcription of JA-inducible genes AtVSP2 and $M Y C 2$, JA/ET-inducible genes $P R 3$ and $P D F 1.2$, ET-inducible gene $P R 4$, and SA-inducible genes $P R 1, P R 2$, and $P R 5$ was analysed by real-time quantitative RT-PCR (Fig. 6). The plants treated with B16 and B17 had higher expression of the SA-dependent marker gene PR-1 (more than 6-fold and 47-fold, respectively). B17 treatment also increased the expression of PR5(8.5-fold). In the plants treated with B16 and B17, the expression of ET-inducible marker gene PR4, JA-inducible genes $M Y C 2$ and JA/ET-inducible marker gene PDF1.2 was upregulated. In the experiments, JA/ETinducible gene $P R 3$ and SA-inducible gene $P R 2$ were not expressed noticeably $(<2$-fold).

Notably, although B16 and B17 simultaneously induced the upregulation of SA- or JA/ET-dependent genes, the expression levels were different obviously. The JA/ETdependent marker gene PDF1.2 was expressed at 557.05 and 125.51 times higher levels in the B16- and B17-treated plants, respectively, than in the control. However, the SA- dependent marker gene PR1 was expressed at 6.48- and 47.72- times higher level in the B16- and B17-treated plants, respectively, than in the control. This result indicated that JA and ET might be involved in the B16- and B17-induced resistance, though with different patterns at the molecular level.

\section{B16- and B17-triggered transcriptomic changes}

To elucidate the molecular mechanism of B16- and B17-induced plant disease resistance and differences in biological activity, we profiled the responses triggered in 14-d-old plate-grown $A$. thaliana seedlings treated with $100 \mu \mathrm{M}$ B16 or B17 for 12 and $24 \mathrm{~h}$ by mRNA sequencing (mRNAseq). As controls, we used a mock treatment (solvent only). MeJA (which is readily converted to JA) was set up as a positive control because the JA-dependent gene PDF1.2 was induced to the highest level among all the tested genes in B16- and B17-treated Col-0 A. thaliana. All the differentially expressed genes (DEGs) are listed in Additional file 4: Data set S1.

At $12 \mathrm{~h}$, a total of 863 genes exhibited significantly altered transcript levels in the B16 treatment (B16-12), with 162 genes upregulated and 702 genes downregulated. In the B17-12 (treated with B17 for $12 \mathrm{~h}$ ) treatment, the number of differentially expressed genes (DEGs) was slightly lower (514 DEGs) than that in the B16-12 treatment, with 98 upregulated genes and 416 down-regulated genes. As a control, the exogenous MeJA-12 treatment (treated with MeJA $12 \mathrm{~h}$ ) induced 682 DEGs, including 323 DEGs (more than 47\%) that were also induced in the B16 treatment and 268 DEGs (more than 39\%) that were also induced in the B17 treatment (Fig. 7), showing a large overlap among B16, B17 and MeJA. This finding suggests that B16 and B17 might mimic some JA functions to activate the transduction of plant defence signals. 


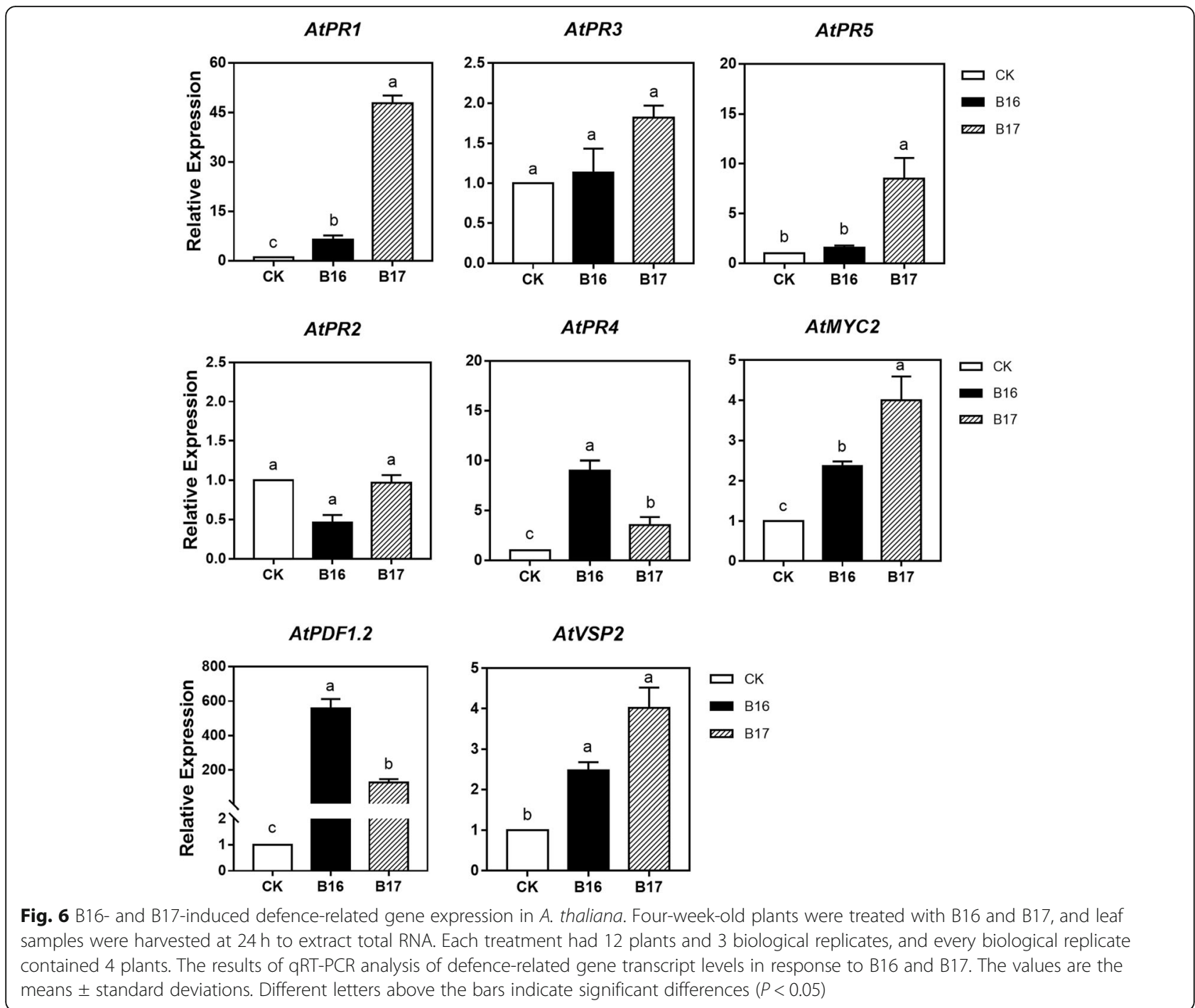

Highly significantly enriched Gene Ontology (GO) terms in the B16-12 and B17-12 set determined based on the Gene Ontology database suggested that the collective roles of the B16-12 genes were mainly enriched in "regulation of plant-type hypersensitive response (GO:0010363)", "response to abscisic acid (GO:0009737)", "protein targeting to membrane (GO:0006612)", "response to ethylene (GO: 0009723)" and "response to jasmonic acid (GO:0009753)". In addition to "response to ethylene (GO:0009723)", "response to jasmonic acid (GO:0009753)" and "regulation of plant-type hypersensitive response (GO:0010363)", B17-12 genes were enriched in the GO term "response to chitin (GO:0010200)" (Table 2). Chitin, which is a polymer of Nacetyl-D-glucosamine (NAG), is a common PAMP causing plant immunity [20, 21]. B17-induced DEGs significantly enriched the GO terms "response to chitin" and "protein targeting to membrane", suggesting that B17 may be identified by immune receptor proteins on the cell membrane as a PAMP and could activate the chitin signal transduction pathway. The GO term "response to chitin" was enriched in only the B17-treated plants and not in the B16-treated plants, indicating that the 3,4-dihydroxy-3-methyl-2-pentanone receptor had structural specificity, which may explain why B16 and B17 showed significant differences in the above experiment. B16- and B17-induced DEGs mostly enriched defence-related GO terms, such as those associated with the regulation of plant-type hypersensitive responses or responses to phytohormones, once again showing that B16 and B17 are successful elicitors in plants.

At 24 $\mathrm{h}$, the sets of B16-24 and B17-24 DEGs were substantially smaller than at previous timepoints (173 genes and 84 genes, respectively, Table 2). As a control, MeJAinduced DEGs also exhibited reduced numbers at $24 \mathrm{~h}$ (only 155 genes). When stimulated by biotic or abiotic stress, plants quickly transmit the defence signal throughout their bodies by adjusting the $\mathrm{Ca}^{2+}$ concentration, thereby inducing a defence response, such as increased 

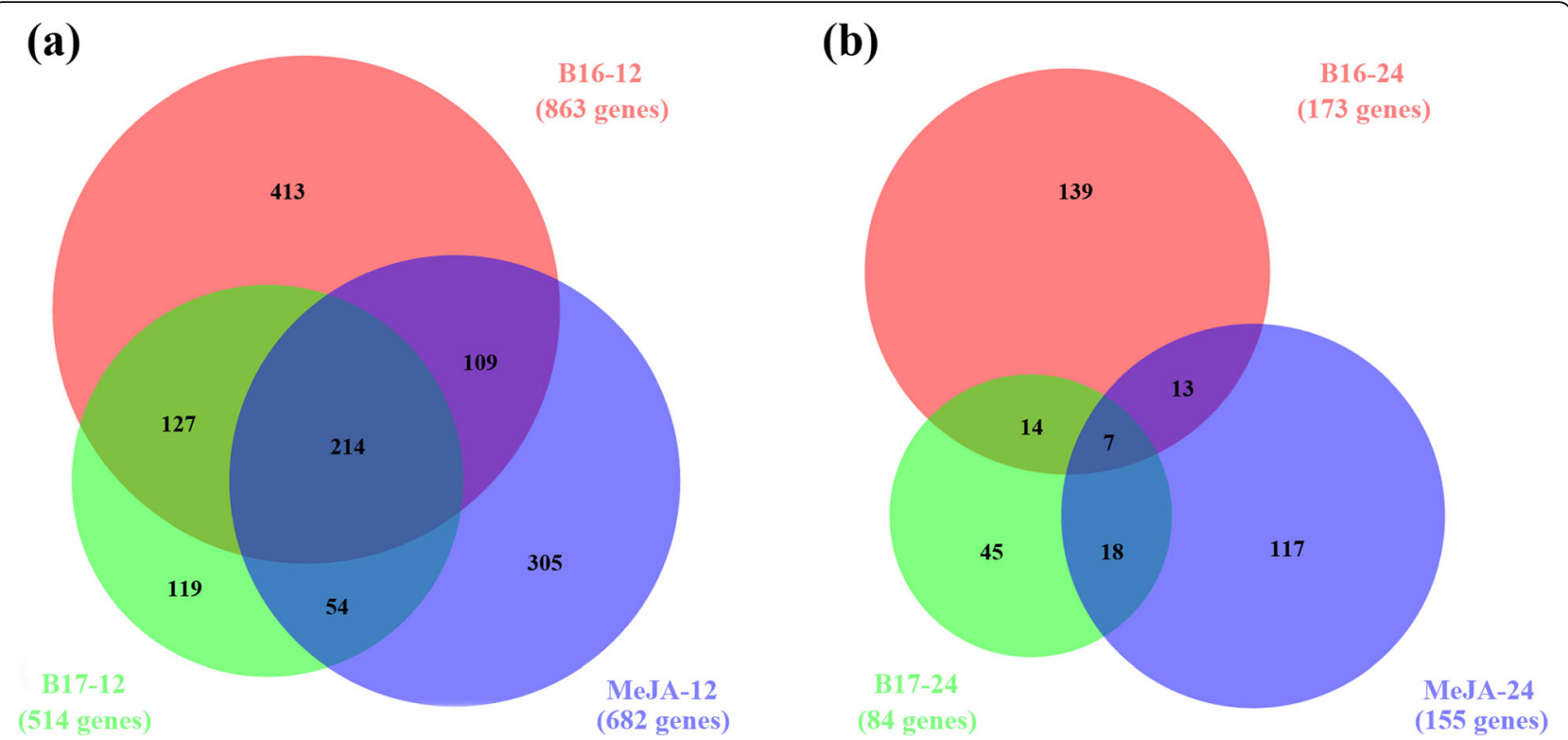

Fig. 7 B16- and B17-triggered transcriptomic changes. Venn diagram analysis highlights the differences and similarities between the gene sets that were triggered by $100 \mu \mathrm{M} \mathrm{B16}$ and B17 in A. thaliana Col-0 plants. (a) Gene sets from plants treated for $12 \mathrm{~h}$ with different compounds. (b) Gene sets from plants treated for $24 \mathrm{~h}$ with different compounds

expression of defence marker genes and accumulation of JA and JA-Ile [22]. This process is rapid and takes only 30 to $60 \mathrm{~min}$ to complete [22]. Therefore, at $24 \mathrm{~h}$, we observed that the number of B16-, B17- and MeJAinduced DEGs decreased. However, the DEGs induced by B16 and B17 featured the enriched term "DNA-templated transcription, elongation (GO:0006354)" (Table 2), which indicates that the early defence signals activate the transcription and translation of downstream defence genes. The DEGs were also enriched in the term "generation of precursor metabolites and energy (GO:0006091)" and the terms related to photosynthesis. There is correlation between defense responses and increasing demands for energy. In the defense responses of plants, plant respiration is highly stimulated [23]. According to the studies on plant defence and photosynthesis, photosynthetic metabolism is locally inhibited in plant defense responses [24, 25]. Photosynthetic apparatus has high sensitivity to ROIs produced during the defence-associated oxidative burs [24].

Taken together, the results show that there were two clearly recognizable trends for 3,4-dihydroxy-3-methyl2-pentanone-induced transcriptional changes at both 12 and 24h: (1) B16 and B17 triggered a substantial number of significantly differentially expressed genes and (2) enriched defence-related GO terms, such as regulation of plant-type hypersensitivity, response to oxidative stress and response to phytohormones (Table 2). In addition, B16, B17 and MeJA co-induced abundant DEGs, suggesting that B16 and B17 act as partial agonists of the plant defence hormone JA.

\section{Discussion}

After sensing characteristic microbe- or pathogen-associated molecular patterns (MAMPs or PAMPs), plant cell surface pattern recognition receptors will activate the pattern-triggered immunity. PGPR-produced metabolites can enhance plant self-immunity [26]. It was found that 2,3-Butandiol isolated from Bacillus subtilis GB03 trigger ISR, and transgenic lines of $B$. subtilis that secreted reduced levels of 2,3-butanediol conferred decreased the resistance to $A$. thaliana against pathogen infection [1], which indicates that PGPR metabolites contribute substantially to ISR. Bacillus subtilis HN09, as a rhizobacterium that can promote plant growth, was isolated from neem rhizospheric soil. In our previous work, we found that HN09 could successfully control tomato Fusarium crown and root rot [27], but the mechanism underlying the induction of disease resistance is not clear. Kutschera et al. [28] reported that immunity in A. thaliana plants can be triggered by bacterial medium-chain 3-hydroxy fatty acid metabolites. Hence, we tested whether HN09 metabolites could induce plant resistance. The data showed that only treatment with HN09-C did not enhance $A$. thaliana resistance to DC3000, but the HN09-FB and HN09-S treatments significantly reduced DC3000 growth in leaves (Fig. 1), suggesting that HN09-induced disease resistance depends on its metabolites.

For the separation of HN09 secondary metabolites, we obtained two compounds, namely, B16 and B17 (Fig. 2), which could induce systemic resistance in A. thaliana. B16 has the same chemical structure as B17, but these 
Table 2 Set of A. thaliana genes significantly differentially expressed in response to B16 or B17 treatment in plate-grown Col-0 seedlings

\begin{tabular}{|c|c|c|c|c|}
\hline Treatment & Enriched GO terms ${ }^{\mathrm{a}}$ & NumDElnCat & NumlnCat & $P$ value \\
\hline \multirow[t]{7}{*}{ B16-12 } & Protein targeting to membrane (GO:0006612) & 40 & 364 & 3.55E-11 \\
\hline & Regulation of plant-type hypersensitive response (GO:0010363) & 40 & 366 & 3.55E-11 \\
\hline & Response to abscisic acid (GO:0009737) & 43 & 450 & $3.12 \mathrm{E}-10$ \\
\hline & Response to ethylene (GO:0009723) & 30 & 253 & 3.49E-09 \\
\hline & Response to jasmonic acid (GO:0009753) & 26 & 262 & 2.35E-06 \\
\hline & Response to oxidative stress (GO:0006979) & 21 & 181 & $3.76 \mathrm{E}-06$ \\
\hline & Systemic acquired resistance (GO:0009627) & 23 & 243 & 2.83E-05 \\
\hline \multirow[t]{10}{*}{ B17-12 } & Response to ethylene (GO:0009723) & 30 & 253 & $2.72 \mathrm{E}-14$ \\
\hline & Regulation of plant-type hypersensitive response (GO:0010363) & 33 & 366 & 7.93E-13 \\
\hline & Systemic acquired resistance (GO:0009627) & 27 & 243 & $1.54 \mathrm{E}-12$ \\
\hline & Defense response to fungus (GO:0050832) & 30 & 314 & 1.75E-12 \\
\hline & Response to jasmonic acid (GO:0009753) & 26 & 262 & $3.76 \mathrm{E}-11$ \\
\hline & Salicylic acid biosynthetic process (GO:0009697) & 23 & 208 & 7.49E-11 \\
\hline & Systemic acquired resistance, salicylic acid mediated signalling pathway (GO:0009862) & 25 & 251 & 7.49E-11 \\
\hline & Response to chitin (GO:0010200) & 31 & 420 & $3.19 \mathrm{E}-10$ \\
\hline & Jasmonic acid mediated signalling pathway (GO:0009867) & 25 & 275 & $4.91 \mathrm{E}-10$ \\
\hline & Defence response to bacterium (GO:0042742) & 28 & 359 & $9.09 \mathrm{E}-10$ \\
\hline \multirow[t]{4}{*}{ B16-24 } & Generation of precursor metabolites and energy (GO:0006091) & 15 & 67 & $2.73 \mathrm{E}-17$ \\
\hline & DNA-templated transcription, elongation (GO:0006354) & 15 & 124 & $2.38 \mathrm{E}-13$ \\
\hline & Photosynthesis (GO:0015979) & 17 & 189 & $2.38 \mathrm{E}-13$ \\
\hline & Translation (GO:0006412) & 11 & 364 & 0.002746 \\
\hline \multirow[t]{6}{*}{ B17-24 } & Generation of precursor metabolites and energy (GO:0006091) & 7 & 67 & $1.14 \mathrm{E}-06$ \\
\hline & Photosynthesis (GO:0015979) & 9 & 189 & $1.96 \mathrm{E}-06$ \\
\hline & DNA-templated transcription, elongation (GO:0006354) & 7 & 124 & $2.92 \mathrm{E}-05$ \\
\hline & Systemic acquired resistance, salicylic acid mediated signalling pathway (GO:0009862) & 8 & 251 & 0.000184 \\
\hline & Regulation of hydrogen peroxide metabolic process (GO:0010310) & 7 & 183 & 0.000250 \\
\hline & Response to bacterium (GO:0009617) & 6 & 172 & 0.002197 \\
\hline
\end{tabular}

Listed are the biological functions of the significantly enriched GO terms based on the Gene Ontology database (http://www.geneontology.org/)

compounds differ in stereoconfiguration. Numerous studies have shown that differences in stereoconfiguration can significantly affect the affinity between a compound and its receptor protein, which in turn affects the bioactivity of the compound $[29,30]$. This phenomenon has also been observed in the study of elicitors. It was observed that the $(2 R, 3 R)$ form plays a main role in 2,3-butanediolinduced resistance to Erwinia carotovora subsp. carotovora, but the $(2 S, 3 S)$ form does not play such a role $[1,6]$. Kutschera et al. [28] also found that (R)-3-hydroxydecanoic acid induced stronger immune signalling than $(\mathrm{S})$-3hydroxydecanoic acid. In the $A$. thaliana phenotype experiment, we observed similar results, demonstrating that the 4-dihydroxy-3-methyl-2-pentanone threo-isomer B16 exhibited more effective biocontrol of DC3000 than the erythro-isomer B17 (Fig. 3). In addition, B16 was also better than Mix, which indicates that one of the B16
$(3 R, 4 S)$ or $(3 S, 4 R)$ isomers may be the optimal configuration for triggering plant ISR against DC3000.

In the callose deposition experiment, B16- and B17treated plants advanced and enhanced cellular defence responses against the pathogen DC3000 (Fig. 4). Callose deposition is an important cellular defence response in plants, preventing the spread of pathogens [2]. Pseudomonas syringae effectors can induce callose deposition in susceptible $A$. thaliana plants [31]. Moreover, we observed a significant difference between B16 and B17 at the cellular level in the triggering of plant ISR (Fig. 4), which was accordance with the phenotypic experiment results.

Generally, ISR depends on the JA or ET signalling pathway, while systemic acquired resistance (SAR) is dependent on the SA signalling pathway [22]. However, many new studies have demonstrated that ISR also involves SA signalling pathway. For instance, SA signalling 
pathway plays an important role in inducing systemic resistance to colonization by Trichoderma asperellum SKT-1. JA/ET and SA signalling pathways act together for induction of resistance against the culture filtrate of this organism [32]. Similarly, the expression of SA, JA and ET signalling marker genes was primed by ISR triggered by a long-chain volatile isolated from Paenibacillus polymyxa E681 [33]. In our study, the SA, JA and ET signalling pathway gene transcription levels were upregulated in the B16- and B17- treated plants (Fig. 6), which indicate that the B16- and B17-induced defence in $A$. thaliana involves both JA/ET and SA signalling. On the other hand, RNA-Seq data also exhibited that among B16and B17-induced DEGs the GO terms related to response to JA or ET (GO:0009723; GO:0009753, Table 2 and Additional file 5: Data set S2) were significantly enriched. Also, few DEGs enriched SA-related GO terms (GO:0009862; GO:0009697 Additional file 5: Data set S2). The JA response is a typical mechanism of ISR induced by beneficial microorganisms. In addition, B16 and B17 were isolated from the PGPR Bacillus subtilis HN09. Thus, we hypothesize that the JA/ET signalling pathway plays a dominant role in B16- and B17-elicited plant immunity and that the SA signalling pathway is also involved in this process. However, SA-JA-ET signalling is associated with complex cross-talk, and we did not have enough evidence to elucidate the specific mechanism of action between B16/B17 and the SA-JA-ET signalling pathway in this study, but we look forward to further investigating this mechanism in subsequent research.

Interestingly, B16 and B17 are a pair of chiral isomeric compounds that not only differ in configuration but also differ significantly in effect. With a high degree of structural specificity in both receptors and complexes, the stereoconfiguration of a compound greatly affects its biological activity. The natural product $(+)$-coronatine induces protein-protein interactions between CORONATINE INSENSITIVE1 (COI1; the F-box subunit of the skp/Cullin/F-box-type ubiquitin ligase complex) and JASMONATE ZIM DOMAIN (JAZ) transcriptional repressor proteins, causing plant growth inhibition or senescence and plant defence responses [29]. However, a stereochemical isomer of coronatine can interact with only JAZ9 and JAZ10, not other JAZ isoforms, without a tradeoff between growth and defence [34]. In this study, the differences in the binding mode and intensity of B16 or B17 and receptors upstream of the plant immune system might have caused the differences in downstream defence responses, such as callose deposition, defence-related enzyme activity and defence-related gene expression.

RNA-seq showed that many DEGs were induced after B16 or B17 treatment compared with the water-treated control (Fig. 7). Through GO enrichment analysis, we found that these DEGs are significantly enriched in pathways associated with plant disease resistance (Table 2), once again showing that B16 and B17 are successful elicitors in plants.

\section{Conclusion}

We isolated and identified a new elicitor, 3,4-dihydroxy-3methyl-2-pentanone, from the metabolites of the plant growth-promoting rhizobacterium Bacillus subtilis HN09. 3,4-dihydroxy-3-methyl-2-pentanone induced plant resistance and exhibits conformational specificity, and the threo-isomer B16 and erythro-isomer B17 induced significant differences in disease resistance at the phenotypic, cellular and molecular levels. Our data showed that B16 induced a stronger defence response than B17 in all the experiments and that the plant hormone SA, JA and ET signalling pathways were involved in this defence response. This study provided new insights into the roles of bacterial metabolites as initiators of defence responses in plants, further opening up the possibility of identifying novel chemical inducers through rational design.

\section{Methods}

Plants, bacterial strains, and growth conditions

In the experiments, $A$. thaliana (ecotype Columbia, Col-0) seeds were acquired from the Arabidopsis Biological Resource Center (https://abrc.osu.edu/). After soaked overnight in cold water at $4{ }^{\circ} \mathrm{C}$, the seeds were planted in peat soil in pots. Two-week-old seeds were grown in $200-\mathrm{mL}$ pots under fluorescent lights $\left(100 \mu \mathrm{E} \mathrm{m}^{-2} \mathrm{~s}^{-1}, 23^{\circ} \mathrm{C}, 10 \mathrm{~h}\right.$ of light $/ 14 \mathrm{~h}$ of dark).

We grew the challenge pathogen Pseudomonas syringae pv. tomato DC3000 overnight at $28^{\circ} \mathrm{C}$ in liquid King's medium B (KB) [2] $\left(20 \mathrm{~g} \cdot \mathrm{L}^{-1}\right.$ peptone, $1.5 \mathrm{~g} \cdot \mathrm{L}^{-1}$ $\mathrm{MgSO}_{4}, 1.5 \mathrm{~g} \cdot \mathrm{L}^{-1} \mathrm{~K}_{2} \mathrm{HPO}_{4}$, and $10 \mathrm{~mL} \cdot \mathrm{L}^{-1}$ glycerinum) which contained $50 \mathrm{mg} \cdot \mathrm{L}^{-1}$ rifampicin. Centrifugation $(2000 \times \mathrm{g}, 3 \mathrm{~min})$ was conducted to pellet the cultured DC3000 cells, which were washed with sterile water and resuspended in $10 \mathrm{mM} \mathrm{MgSO}$ containing the surfactant Silwet L-77 (Sigma) at 0.01\% (v/v). Afterwards, it was adjusted to $\mathrm{OD}_{600}=0.01$ for gradient dilution to the required concentration.

In this experiment, Bacillus subtilis HN09 was tested, which was isolated from neem rhizospheric soil from the Insecticidal Plants Arboretum of South China Agricultural University, Guangdong Province, China [27]. We grew HN09 in yeast extract-peptone-dextrose (YPD) liquid medium $\left(3 \mathrm{~g} \cdot \mathrm{L}^{-1}\right.$ beef extract, $5 \mathrm{~g} \cdot \mathrm{L}^{-1}$ yeast powder, $20 \mathrm{~g} \cdot \mathrm{L}^{-1}$ peptone, $12.5 \mathrm{~g} \cdot \mathrm{L}^{-1}$ glucose) for $24 \mathrm{~h}$ at $28^{\circ} \mathrm{C}$. The bacterial cells were pelleted by centrifugation $(2000 \times \mathrm{g}, 3 \mathrm{~min})$, resuspended in sterile $0.85 \% \mathrm{NaCl}$, and adjusted to $\mathrm{OD}_{600}=0.10$ for the HN09 cell treatment (HNO9-C). The remaining supernatant containing HN09 metabolites was filter sterilized with a $0.2 \mu \mathrm{m}$ syringe-driven filter as the NH09 supernatant 
treatment (HN09-S). The HN09 fermentation (HN09-FB) treatment contained both HN09 bacterial cells and metabolites, and the concentration was adjusted to $\mathrm{OD}_{600}=0.10$.

\section{Metabolite extraction and isolation}

petroleum ether, $\mathrm{CHCl}_{3}$, EtOAc, and $n-\mathrm{BuOH}$ were used to extract the culture filtrate of HN09 sequentially three times to generate dried petroleum ether-soluble $(29.87 \mathrm{~g})$, $\mathrm{CHCl}_{3}$-soluble (16.03 g), EtOAc-soluble (30.6 g), and nbutyl alcohol-soluble $(80.15 \mathrm{~g})$ extracts. The EtOAc-soluble extract was subjected to passage over a silica gel column (100-200 mesh) which was eluted with $\mathrm{CHCl}_{3}$-methanol mixtures of increasing polarities (100:0-90:10-80:20-70: 30-60:40-50:50, v/v). A total of 10 fractions (E1-E10) were obtained. Fraction E4 (7.4 g), which was obtained by elution with $\mathrm{CHCl}_{3}-\mathrm{MeOH}$ (80:20), was rechromatographed on a Develosil ODS $(10 \mu \mathrm{m}$, Nomura Chemical Co. Ltd., Japan) column. Moreover, 16 subfractions (E4-1-E4-16) was obtained by eluting Fraction $\mathrm{E} 4$ with $\mathrm{MeOH}-\mathrm{H}_{2} \mathrm{O}$ mixtures $(3: 7,1: 1$, and $7: 3)$. preparative HPLC was used to separate the subfraction E4-1, which was run with a Shimadzu RID-10A refractive index detector and a Shimadzu LC-6 AD pump by taking a YMCpack ODS-A C18 column $(5 \mu \mathrm{m}, 250 \times 20 \mathrm{~mm})$ and $\mathrm{MeOH}$-water mixture $(7: 93, \mathrm{v} / \mathrm{v})$ as the mobile phase to generate B16 (2.86 g) and B17 (1.76 g).

\section{Plant treatment and pathogen inoculation}

After $A$. thaliana growth in pots for 2 weeks, $10 \mathrm{~mL}$ of HN09-S, HN09-C and HN09-FB was poured over the surface of each pot. An equal volume of sterile $10 \mathrm{mM}$ $\mathrm{MgSO}_{4}$ was used for control treatment. Five days after treatment, the leaves were sprayed with a cell suspension of the virulent pathogen Pseudomonas syringae pv. tomato $\mathrm{DC} 3000$ at $\mathrm{OD}_{600}=0.01$ until fine droplets cover all leaves to challenge-inoculate the plants of all treatments. For the HN09 metabolite B16 and B17 treatments, four-week-old $A$. thaliana plants were treated with $100 \mu \mathrm{M}$ B16, B17, Mix (a mixture of B16 and B17), $\mathrm{BTH}$ and $\mathrm{MgSO}_{4}$ by spraying the leaves. Twenty-four hours after the treatment, the DC3000 pathogen was inoculated by injecting bacteria (diluted to $\mathrm{OD}_{600}=0.001$ ) into leaves through the stomata on the undersides of the leaves. After inoculation, the plants were maintained for 3 days at $100 \%$ relative humidity in a dew chamber and then transferred to a growth chamber $\left(100 \mu \mathrm{E} \mathrm{m}^{-2} \mathrm{~s}^{-1}\right.$, $23^{\circ} \mathrm{C}, 10 \mathrm{~h}$ of light $/ 14 \mathrm{~h}$ of dark).

\section{Quantification of DC3000 in A. thaliana leaves}

The leaves were sampled on the fifth day after inoculation (dpi) to determine the density of DC3000 in A. thaliana leaves. Each treatment had 12 plants, and 3 representative leaves per plant were obtained for quantification of DC3000 density. All samples were weighed, soaked for $30 \mathrm{~s}$ in $75 \%$ ethanol for surface sterilization, washed with sterile distilled water three times, and then homogenized with a sterile mortar and pestle with 10 $\mathrm{mM} \mathrm{MgSO}$. Appropriate dilutions were plated onto $\mathrm{KB}$ medium supplemented with $100 \mathrm{mg} \cdot \mathrm{L}^{-1}$ cycloheximide and $50 \mathrm{mg} \cdot \mathrm{L}^{-1}$ rifampicin, which were incubated at $28^{\circ} \mathrm{C}$. After 48-h incubation, we counted the number of colonies of the rifampicin-resistant pathogen strain DC3000. The bacterial density was expressed as CFU per gram of leaf fresh weight $\left(\mathrm{CFU} \cdot \mathrm{g}^{-1}\right)$. This experiment was conducted four times. A least significant difference (LSD) test $(P=0.05)$ was carried out for mean comparison. LSD results and standard errors were recorded.

\section{Callose deposition}

A. thaliana leaves were sampled at $24 \mathrm{hpi}$ and treated as described by Niu [2], so that callose deposition can be determined. Each treatment had 6 plants, and 3 representative leaves per plant were obtained for analysis of callose deposition. Briefly, all leaves were soaked in 40 $\mathrm{mL}$ of destaining solution (ethanol/water/lactic acid/glycerol/phenol = 8:1:1:1:1 (v/v/v/v/v)) and vacuum-infiltrated for $10 \mathrm{~min}$. Then, the chlorophyll was cleared by incubating the samples for $30 \mathrm{~min}$ in a $60^{\circ} \mathrm{C}$ water bath. After rinsing with water, the chlorophyll-free leaves were soaked for 2 to $4 \mathrm{~h}$ in the dark in $0.01 \%(\mathrm{w} / \mathrm{v})$ aniline blue staining solution with $150 \mathrm{mM} \mathrm{K} \mathrm{KPO}_{4}(\mathrm{pH} 9.5)$. Finally, leaves were observed and photographed under an Olympus BX51 microscope with a UV excitation filter (Olympus, Shinjuku, Tokyo, Japan). The pixels of the callose deposition area were calculated by Adobe Photoshop 2015 CC and then converted to area according to the number of pixels per square millimetre.

\section{Enzyme activity assay}

After ground in liquid nitrogen, $A$. thaliana leaves $(0.5 \mathrm{~g})$ were homogenized with $1.5 \mathrm{~mL}$ of phosphate buffer (50 mM, pH 7.8). We centrifuged the extracts at 10,000 rpm for $15 \mathrm{~min}$ at $4{ }^{\circ} \mathrm{C}$. The activity of phenylalanine ammonialyase (PAL) and peroxidase (POD) was determined by supernatant. POD enzyme activity was assayed as follows [35]. The assay mixture contained $0.1 \mathrm{~mL}$ of enzyme solution, $0.2 \mathrm{~mL}$ of $4 \%(\mathrm{v} / \mathrm{v})$ guaiacol, $0.2 \mathrm{~mL}$ of $0.46 \%(\mathrm{v} / \mathrm{v})$ $\mathrm{H}_{2} \mathrm{O}_{2}$, and $2.5 \mathrm{~mL}$ of $0.1 \mathrm{M}$ sodium phosphate buffer $(\mathrm{pH}$ 7.0). We recorded the increase in absorbance at $470 \mathrm{~nm}$ at $25^{\circ} \mathrm{C}$ for $3 \mathrm{~min}$. One unit of POD activity was the amount of enzyme leading to a change of 0.01 in absorbance per minute and calculated according to the following formula: POD enzyme activity $[\mathrm{U} /(\mathrm{g} \cdot \mathrm{min})]=\Delta \mathrm{OD}_{470}$. $\mathrm{D} /(0.01 \cdot \mathrm{W} \cdot \mathrm{t})\left(\Delta \mathrm{OD}_{470}\right.$ : change in absorbance; $\mathrm{D}$ : dilution factor; W: fresh weight; t: reaction time). We incubated the assay mixture containing $0.1 \mathrm{~mL}$ of enzyme extract, L-phenylalanine $(2 \mathrm{mM})$ and sodium borate buffer $(20 \mathrm{mM}, \mathrm{pH} 8.8)$ at $30^{\circ} \mathrm{C}$ for $1 \mathrm{~h}$ for PAL activity. 
The 0.01 -unit increase in absorbance at $290 \mathrm{~nm}$ caused by the formation of trans-cinnamate was measured. PAL enzyme activity $[\mathrm{U} /(\mathrm{g} \cdot \mathrm{h})]=\Delta \mathrm{OD}_{290} \cdot \mathrm{D} /(0.01 \cdot \mathrm{W} \cdot \mathrm{t})[36]$. $\beta-$ 1,3-A previously described method was modified to determine glucanase activity [37]. $5 \mathrm{~mL}$ of sodium acetate buffer (50 mM, pH 5.0) was used to homogenize one gram of leaf sample, which was further centrifuged at $4{ }^{\circ} \mathrm{C}$ for $20 \mathrm{~min}$ at $8000 \mathrm{rpm}$ to obtain the crude extract. In order to detect $\beta-1$, 3 -glucanase, the mixture of $100 \mathrm{~mL}$ of crude extract and $100 \mathrm{~mL}$ of $1 \%$ laminarin was incubated for $60 \mathrm{~min}$ at $37^{\circ} \mathrm{C}$. The sample was heated for $10 \mathrm{~min}$ in boiling water to terminate the reaction. The amount of enzyme required to catalyse the production of $1 \mathrm{mg}$ of glucose equivalent $\mathrm{h}^{-1}$ at $37^{\circ} \mathrm{C}$ was one unit of $\beta$-1,3-glucanase activity.

\section{Real-time RT-PCR analysis}

We performed quantitative RT-PCR as previously described [27] in order to monitor defence-related gene expression. The Plant RNA Kit (OMEGA, USA) was used to extract total RNA from the cotyledons. The ratio of the absorbance at 260 and $280 \mathrm{~nm}$ was determined by ultraviolet spectrophotometry to measure RNA quality. In order to remove contaminating genomic DNA, the first-strand complementary DNA (cDNA) was synthesize by $1 \mu \mathrm{g}$ of total RNA digested by DNase I (NEB, USA) through iScript reverse transcription (Bio-Rad, USA). Primers were synthesized by BGI Tech Solutions Co., Ltd. (Shenzhen, Guangdong, China). Additional file 3: Table S1 lists the primer sequences [5]. We used a CFX Connect real-time PCR detection system (Bio-Rad, USA) to perform PCR in optical 96-well plates with a total volume of $20 \mu \mathrm{L}$, containing $10 \mu \mathrm{L}$ of $2 \times$ IQ SYBR Green Supermix reagent (Bio-Rad, USA), $0.5 \mu \mathrm{L}$ of each of the two gene-specific primers $\left(10 \mathrm{pmol} \mu \mathrm{L}^{-1}\right), 1 \mu \mathrm{L}$ of

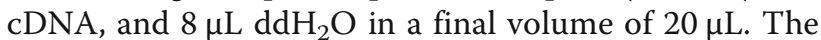
$\Delta \Delta C T$ (cycle threshold) method was employed to normalize the relative expression levels of the selected genes to those of the reference gene AtUBQ5 using the following equation: amount of target $=2^{-\Delta \Delta C T}$, where $\Delta \Delta \mathrm{CT}=\left(\mathrm{C}_{\mathrm{T}, \text { target }}-\mathrm{C}_{\mathrm{T}, \mathrm{ubq} 5}\right)_{\text {Treatment }}-\left(\mathrm{C}_{\mathrm{T} \text {,target }}-\right.$ $\left.\mathrm{C}_{\mathrm{T}, \mathrm{ubq5}}\right)_{\mathrm{Ck}}$ [38]. Each treatment had 12 plants and 3 biological replicates, and every biological replicate contained 4 plants.

\section{RNA-Seq analysis}

The rosette leaves were dipped into a mock, B16, B17, or MeJA (Sigma, Shanghai, China) solution to treat the fourweek-old A. thaliana plants. There were $0.015 \%$ (v/v) Silwet L77 and $100 \mu \mathrm{M}$ B16, B17 and MeJA in the B16, B17 and MeJA solutions, respectively. The mock solution contained 0.015\% (v/v) Silwet L77 (Sigma). After treatment for $12 \mathrm{~h}$ and $24 \mathrm{~h}$, we harvested the sixth leaf (counted from the oldest true leaf to the youngest leaf) from individual $A$. thaliana plants, which was snap frozen in liquid nitrogen
[39]. Leaves from three potted plants for each treatment and each time point were mixed as a single sample for sequencing. RNA-seq was completed by the Hengchuang Gene Technology Company (ShenZhen, Guangdong, China). The raw RNA-Seq read data are deposited in the Sequence Read Archive (http://www.ncbi.nlm.nih.gov/sra/; BioProject ID: PRJNA555596). The NEBNext ${ }^{\circ}$ Ultra $^{\mathrm{Tu}}$ RNA Library Prep Kit for Illumina ${ }^{\circ}$ (NEB, USA) was used to generate sequencing libraries according to the manufacturer's instructions. DEGSeq was used for differential expression analysis [40]. $q$ value (or FDR) $<0.01$ and $\mid \log 2$ (foldchange) $\mid>1$ were the thresholds for significant differential expression. GOseq was used for Gene Ontology (GO) enrichment analysis of differentially expressed genes (DEGs), and the bias of gene length was corrected. GO functional analysis provides $\mathrm{GO}$ functional enrichment analysis for DEGs and GO functional classification annotation for DEGs. The biological functions of enriched GO terms were determined based on the Gene Ontology database (http://www.geneontology.org/).

\section{Additional files}

\begin{abstract}
Additional file 1: Figure S1. Bacillus subtilis HN09 induces defence responses in multiple plant species against diverse pathogens. (a) HN09 enhances systemic resistance to Fusarium oxysporum f. sp. radicis-lycopersici in tomato. Tomato plant roots drenched with HNO9 (optical density at 600 $\mathrm{nm} \mathrm{OD}_{600}=0.1$ ) display a reduction in disease severity in leaves relative to CK-treated (solvent only) plants $7 \mathrm{dpi}(n=4)$. Red boxes mark the symptoms developing from the base of the plant. (b) HNO9 enhances resistance to Magnaporthe oryzae GD00-193 in rice. The roots of two-week-old rice of the generally susceptible variety Lijiangxintuanheigu $(\mathrm{LTH})$ and resistant variety HNBL9 were treated with $\mathrm{HNO}_{0}$ at $\mathrm{OD}_{600}=0.1$; seven days later, the leaves were sprayed with a cell suspension of GD00-193 at $1 \times 10^{5} \mathrm{CFU} / \mathrm{mL}$. Quantitative real-time RT-PCR was used to quantitatively analyse GD00-193 growth on leaves. $X^{2}$ tests were performed for difference significance analysis; ${ }^{* *}$ indicates significant differences at $P<0.01$; ${ }^{* *} P<0.001$. The data shown are representative of at least three independent experiments. (TIF 386 kb)
\end{abstract}

Additional file 2: Figure S2. Growth promotion of $A$. thaliana $\mathrm{Col}-0$ by HN09. One-week-old $A$. thaliana Col-0 sterile plants were treated with HN09, DH5a or sterile water, with the latter two serving as controls. Each treatment had 30 plants. (a) Representative plants of each treatment were photographed 14 days post treatment. (b) Dry weight of each treatment plant. The data presented were from a representative experiment that was repeated three times with similar results. Different letters indicate statistically significant differences between treatments (Fisher's least significant difference; $P<0.05$ ). (TIF 8405 kb)

Additional file 3: Table S1. Primers used in this study. (DOCX $15 \mathrm{~kb}$ ) Additional file 4: Dataset S1. List of DEGs from the B16, B17 and JA treatments in this study. (XLSX 67 kb)

Additional file 5: Dataset S2. Enriched GO terms from the B16, B17 and JA treatment sets of DEGs. (XLSX $29 \mathrm{~kb}$ )

\section{Abbreviations}

BTH: Benzothiadiazole; DEGs: Differentially expressed genes; ET: Ethylene; GO: Gene ontology; ISR: Induced systemic resistance; JA: Jasmonic acid; MAMPs: Microbe-associated molecular patterns; MeJA: Methyl jasmonic acid; PAL: Phenylalanine ammonia-lyase; PAMPs: Pathogen-associated molecular patterns; PGPR: Plant growth-promoting rhizobacterium; POD: Peroxidase; ROS: Reactive oxygen species; SA: Salicylic acid; SAR: Systemic acquired resistance 


\section{Acknowledgements}

We acknowledge Xiaoyi Wei (South China Botanical Garden of the Chinese Academy of Sciences) for guidance with the analysis of the stereoisomeric structures of compounds B16 and B17.

\section{Author contributions}

$\mathrm{FL}$ and $\mathrm{HHX}$ conceived and designed the work. $\mathrm{NL}$ and $\mathrm{XL}$ conducted the experiments and data analyses. LLZ and YQT separated and identified metabolites B16 and B17 from HN09 fermentation broth. FL and DL helped write the manuscript. All the authors read and approved the manuscript.

\section{Funding}

This research was supported by the National Key R\&D Program of China (2017YFD0201100 and 2017YFD0200307), the Project of Science and Technology in Guangdong Province (grant no. 2014A050503056), and the Scientific Project in Guangzhou City (grant no. 201707020013 and 201704030027). The funders did not play any role in the design, collection, analysis, or interpretation of the relevant data or in the writing of the manuscript.

\section{Availability of data and materials}

The data sets supporting the results of this article are included within the article and its additional files. The biological functions of enriched GO terms were determined based on the Gene Ontology database (http:// www.geneontology.org/). The raw RNA-Seq read data are deposited in the Sequence Read Archive (http://www.ncbi.nlm.nih.gov/sra/; BioProject ID: PRJNA555596).

\section{Ethics approval and consent to participate}

Not applicable.

\section{Consent for publication}

Not applicable.

\section{Competing interests}

The authors declare that they have no competing interests.

\section{Author details}

${ }^{1}$ State Key Laboratory for Conservation and Utilization of Subtropical Agro-Bioresources/Key Laboratory of Natural Pesticide and Chemical Biology, Ministry of Education, South China Agricultural University, Guangzhou 510642, China. ${ }^{2}$ Guangdong Province Key Laboratory of Microbial Signals and Disease Control, South China Agricultural University, Guangzhou 510642, China. ${ }^{3}$ Key Laboratory of South Subtropical Fruit Biology and Genetic Resource Utilization, Ministry of Agriculture, Guangdong Academy of Agricultural Sciences, Guangzhou 510640, China.

Received: 9 May 2019 Accepted: 23 August 2019

Published online: 05 September 2019

\section{References}

1. Ryu CM, Farag MA, Hu CH, Reddy MS, Kloepper JW, Paré PW. Bacterial volatiles induce systemic resistance in Arabidopsis. Plant Physiol. 2004;134: 1017-26.

2. Niu DD, Liu HX, Jiang CH, Wang YP, Wang QY, Jin HL, Guo JH. The plant growth-promoting rhizobacterium Bacillus cereus AR156 induces systemic resistance in Arabidopsis thaliana by simultaneously activating salicylateand jasmonate/ethylene-dependent signaling pathways. Mol Plant-Microbe Interact. 2011;24:533-42.

3. Hossain MM, Sultana F, Kubota M, Koyama H, Hyakumachi M. The plant growth-promoting fungus Penicillium simplicissimum GP17-2 induces resistance in Arabidopsis thaliana by activation of multiple defense signals. Plant Cell Physiol. 2007;48:1724-36.

4. Pieterse CM, van Wees SC, van Pelt JA, Knoester M, Laan R, Gerrits H, Weisbeek PJ, van Loon LC. A novel signaling pathway controlling induced systemic resistance in Arabidopsis. Plant Cell. 1998;10:1571-80.

5. Naznin HA, Kiyohara D, Kimura M, Miyazawa M, Shimizu M, Hyakumachi M. Systemic resistance induced by volatile organic compounds emitted by plant growth-promoting Fungi in Arabidopsis thaliana. PLoS One. 2014;9:e868821.
6. Farag MA, Ryu CM, Sumner LW, Paré PW. GC-MS SPME profiling of rhizobacterial volatiles reveals prospective inducers of growth promotion and induced systemic resistance in plants. Phytochemistry. 2006;67:2262-8.

7. Wu G, Liu Y, Xu Y, Zhang G, Shen Q, Zhang R. Exploring elicitors of the beneficial rhizobacterium bacillus amyloliquefaciens SQR9 to induce plant systemic resistance and their interactions with plant signaling pathways. Mol Plant-Microbe Interact. 2018;31:560-7.

8. Vlot AC, Dempsey DA, Klessig DF. Salicylic acid, a multifaceted hormone to combat disease. Annu. Rev. Phytopathol. 2009;47(1):177-206.

9. Loon LCV, Rep M, Pieterse CMJ. Significance of inducible defense-related proteins in infected plants. Annu Rev Phytopathol. 2006;44:135-62.

10. Pieterse CMJ, Zamioudis C, Berendsen RL, Weller DM, Wees SCMV, Bakker PAHM. Induced systemic resistance by beneficial microbes. Annu Rev Phytopathol. 2014;52:347-75.

11. Youngsang K, Choongmin R, Soohyun L, Hyobee P, Han KS, Junghan L, Kyunghee L, Woosik C, Mijeong J, Heekyu K. Proteome analysis of Arabidopsis seedlings exposed to bacterial volatiles. Planta. 2010;232:1355-70.

12. Cortes-Barco AM, Goodwin PH, Hsiang T. Comparison of induced resistance activated by benzothiadiazole, (2R,3R)-butanediol and an isoparaffin mixture against anthracnose of Nicotiana benthamiana. Plant Pathol. 2010;59:643-53.

13. Truitt $\mathrm{CL}$, Paré $\mathrm{PW}$. A plasma membrane protein from zea mays binds with the herbivore elicitor volicitin. Plant Cell. 2004;16:523-33.

14. Ui S, Hosaka T, Watanabe K, Mimura A. Discovery of a new mechanism of 2,3-butanediol stereoisomer formation in Bacillus cereus YUF-4. J Ferment Bioeng. 1998:85:79-83.

15. Kohler A, Schwindling S, Conrath U. Benzothiadiazole-induced priming for potentiated responses to pathogen infection, wounding, and infiltration of water into leaves requires the NPR1/NIM1 gene in Arabidopsis. Plant Physiol. 2002;128(3):1046-56.

16. Rahman A, Kuldau GA, Uddin W. Induction of salicylic acid-mediated defense response in perennial ryegrass against infection by magnaporthe oryzae. Phytopathology. 2014;104(6):614-23.

17. Liu H, Zhou X, Dong N, Liu X, Zhang H, Zhang Z. Expression of a wheat MYB gene in transgenic tobacco enhances resistance to Ralstonia solanacearum, and to drought and salt stresses. Funct Integr Genomic. 2011;11:431-43.

18. Sun J, Li C, Prasad KN, You X, Li L. Membrane deterioration, enzymatic browning and oxidative stress in fresh fruits of three litchi cultivars during six-day storage. Sci Hortic. 2012;148:97-103.

19. Sun JM, Fu JF, Zhou RJ, Su WN, Yan XR. Effects of methyl Jasmonate on Cylindrocarpon root rot development on ginseng. Adv Mater Res. 2013;610:3511-7.

20. Liu T, Liu Z, Song C, Hu Y, Han Z. Chitin-induced dimerization activates a plant immune receptor. Science. 2012;336(6085):1160-4.

21. Cao Y, Liang Y, Tanaka K, Nguyen CT, Jedrzejczak RP, Joachimiak A, Stacey $\mathrm{G}$. The kinase LYK5 is a major chitin receptor in Arabidopsis and forms a chitin-induced complex with related kinase CERK1. Elife. 2014;3:e03766.

22. Toyota M, Spencer D, Sawai-Toyota S, Jiaqi W, Zhang T. Glutamate triggers longdistance, calcium-based plant defense signaling. Science. 2018;361:1112-5.

23. Wasternack C. How jasmonates earned their laurels: past and present. J Plant Growth Regul. 2015;34:761-94.

24. Bolton MD. Primary metabolism and plant defense--fuel for the fire. Mol Plant-Microbe Interact. 2009;22:487.

25. Berger S, Sinha AK, Roitsch T. Plant physiology meets phytopathology: plant primary metabolism and plant-pathogen interactions. J Exp Bot. 2007:58:4019-26.

26. Farag MA, Zhang $H$, Ryu CM. Dynamic chemical communication between plants and bacteria through airborne signals: induced resistance by bacterial volatiles. J Chem Ecol. 2013;39:1007-18.

27. Lin F, Liu N, Lai D, Kang XH, Pang NW, Jiang HK, Xu HH. A formulation of neem cake seeded with Bacillus sp. provides control over tomato Fusarium crown and root rot. Biocontrol Sci Techn. 2017;27:393-407.

28. Kutschera A, Dawid C, Gisch N, Schmid C, Raasch L, Gerster T, Schaffer M, Smakowska-Luzan E, Belkhadir Y, Vlot AC, et al. Bacterial medium-chain 3hydroxy fatty acid metabolites trigger immunity in Arabidopsis plants. Science. 2019;364(6436):178-81.

29. Monte I, Hamberg M, Chini A, Gimenezibanez S, Garcíacasado G, Porzel A, Pazos F, Boter M, Solano R. Rational design of a ligand-based antagonist of jasmonate perception. Nat Chem Biol. 2014;10:671-6.

30. Sheard LB, Tan X, Mao H, Withers J, Ben-Nissan G. Jasmonate perception by inositol-phosphate-potentiated COI1-JAZ co-receptor. Nature. 2010; 468(7322):400-5. 
31. Hauck P, Thilmony R, He SY. A Pseudomonas syringae type III effector suppresses cell wall-based extracellular defense in susceptible Arabidopsis plants. Proc Natl Acad Sci U S A. 2003;100:8577-82.

32. Yoshioka Y, Ichikawa H, Naznin HA, Kogure A, Hyakumachi M. Systemic resistance induced in Arabidopsis thaliana by Trichoderma asperellum SKT-1, a microbial pesticide of seedborne diseases of rice. Pest Manag Sci. 2012;68:60-6.

33. Lee B, Farag MA, Park HB, Kloepper JW, Lee SH, Ryu CM. Induced resistance by a long-chain bacterial volatile: elicitation of plant systemic defense by a C13 volatile produced by Paenibacillus polymyxa. PLoS One. 2012;7:e48744.

34. Takaoka Y, Iwahashi M, Chini A, Saito H, Ishimaru Y. A rationally designed JAZ subtype-selective agonist of jasmonate perception. Nat Commun. 2018; 9:3654-67.

35. Sun J, You X, Li L, Peng H, Su W, Li C, He Q, Liao F. Effects of a phospholipase $\mathrm{D}$ inhibitor on postharvest enzymatic browning and oxidative stress of litchi fruit. Postharvest Biol Technol. 2011;62:288-94.

36. Lu X, Sun D, Li Y, Shi W, Sun G. Pre- and post-harvest salicylic acid treatments alleviate internal browning and maintain quality of winter pineapple fruit. Sci Hortic. 2011;130:97-101.

37. Sun D, Lu X, Hu Y, Li W, Hong K, Mo Y, Cahill DM, Xie J. Methyl jasmonate induced defense responses increase resistance to Fusarium oxysporum f. sp. cubense race 4 in banana. Sci Hortic. 2013;164:484-91.

38. Livak KJ, Schmittgen TD. Analysis of relative gene expression data using realtime quantitative PCR and the $2^{-\Delta \Delta} C T$ method. Methods. 2001;25:402-8.

39. Hickman R, Van Verk MC, Van Dijken AJH, Mendes MP, Vroegop-Vos IA. Architecture and dynamics of the jasmonic acid gene regulatory network. Plant Cell. 2017;29:2086-105.

40. Love Ml, Huber W, Anders S. Moderated estimation of fold change and dispersion for RNA-seq data with DESeq2. Genome Biol. 2014;15(12):550.

\section{Publisher's Note}

Springer Nature remains neutral with regard to jurisdictional claims in published maps and institutional affiliations.

Ready to submit your research? Choose BMC and benefit from:

- fast, convenient online submission

- thorough peer review by experienced researchers in your field

- rapid publication on acceptance

- support for research data, including large and complex data types

- gold Open Access which fosters wider collaboration and increased citations

- maximum visibility for your research: over $100 \mathrm{M}$ website views per year

At $\mathrm{BMC}$, research is always in progress.

Learn more biomedcentral.com/submissions 